\title{
Spartan sport laid bare
}

\section{Edgar Degas's painting of female athletes challenging male competitors in classical Sparta raises subtle questions about gender, politics and sport, explains Martin Kemp.}

The original Olympic Games, first recorded in 776 BC at Olympia, Greece, were driven by the Greek cult of the body beautiful and the body athletic. This is directly reflected in ancient sculptures of the male form. Revered physiques were of two types - the slender and graceful form typified by Apollo, and the rugged muscularity of Hercules.

Among early Greek cultures, the militaristic state of Sparta alone accorded women a status comparable with that of men in the cultivation of an athletic physique. Plutarch tells us that Lycurgus, the severe law-giver of Sparta, "ordered the maidens to exercise themselves with wrestling, running, throwing the quoit, and casting the dart, to the end that the fruit they conceived might, in strong and healthy bodies, take firmer root and find better growth".

This ideal was accompanied by the routine exposure of naked or partially clothed women's bodies, which was seen as modest rather than shameful, with all wantonness excluded. Plutarch says that this "taught them simplicity and a care for good health, and gave them some taste of higher feelings, admitted as they thus were to the field of noble action and glory".

All this contrasts with the better known Athenian culture, in which women were largely subordinated in domestic roles and were certainly not expected to display their flesh. Athenian standards set the tone for subsequent European societies. Yet the Spartan cult of bodily resolution, based on austere physical training and forbearance of pain, has inspired many military and political movements, including the French Revolution. The word spartan, signifying courageous endurance, has entered the modern vocabulary.

Sparta has also bequeathed to us the adjective 'laconic', after the name of the territory Laconia, over which the city of Sparta ruled. The Spartans were renowned for being people of few words, preferring brief utterances and decisive action to literary and rhetorical flourishes.

The singular position of women in Spartan culture attracted the attention of the French artist Hilaire-Germain-Edgar Degas around 1860. Those who know Degas from his famous scenes of contemporary life, especially his bathers, dancers and horse races, may be surprised to find him tackling the kind of ancient subject that was favoured by the conservative academy. Degas, however, made a very modern subject from ancient history.

The painting The Young Spartans was begun

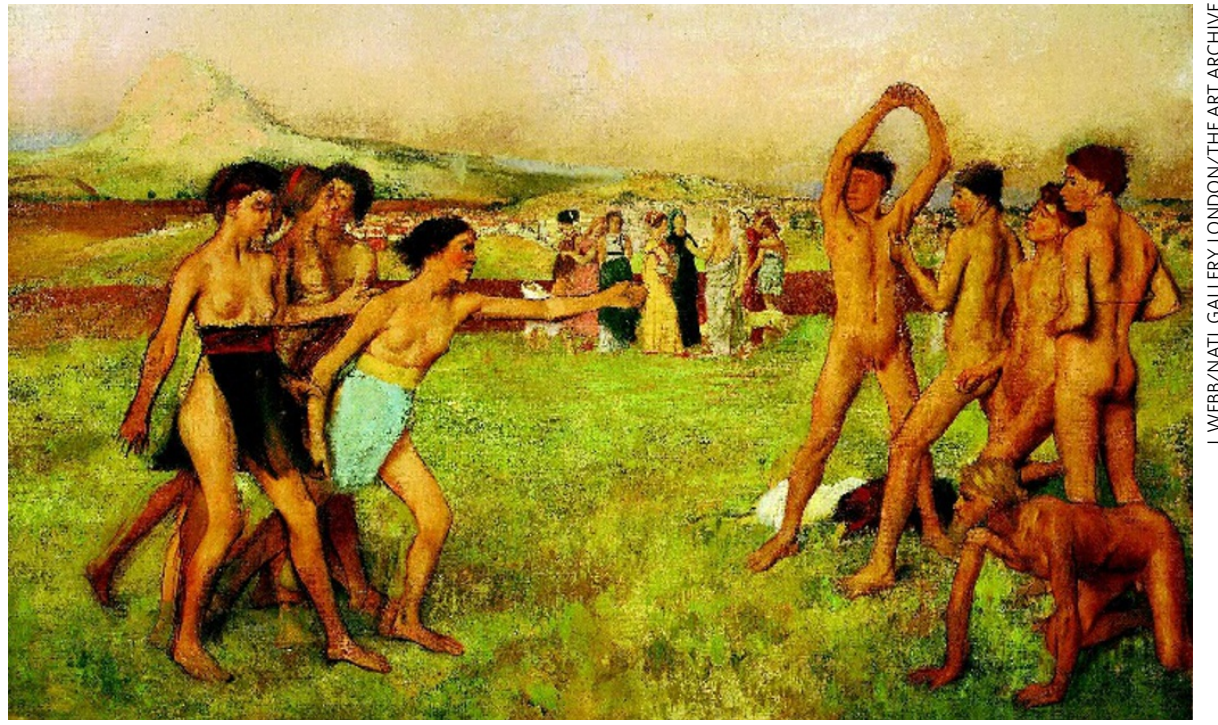

Degas's The Young Spartans portrays an ancient scene yet highlights modern ideas about feminism.

around 1860 and remained in Degas's studio. He planned to exhibit it in partly reworked form at the Fifth Impressionist Exhibition in 1880 , but did not do so. His patron and friend, Diego Martelli, described the subject as "girls who challenge the boys to a race, which decided, in accordance with the law of those people, their submission".

On an open grassy plain, four lightly clad young women confront a group of naked young men, who have cast off their rudimentary garments. The youths posture self-consciously as adolescent males will, exercising a precocious bravado. The leading girl issues a challenge or provocation. In the background, as Degas has testified, is the white-robed Lycurgus with a group of mothers and their children.

Compared with a prior, unfinished version of the painting in the Art Institute of Chicago in Illinois, the antique elements are played down. A classical shrine has been eliminated, and the foreground protagonists have lost their ancient appearance. They are now cast as the kind of lower class Parisian youths whom Degas sometimes sketched.

Degas was deeply interested in physiognomy, ethnography, anthropology and criminology. His famous sculpture of the Little Dancer of Fourteen Years was exhibited in a glass case in 1881 as a 'primitive' ethnographic type, alongside his pastels of criminal physiognomies. His Spartan boys exhibit the kind of profiles with protruding jaw lines that, in a post-Darwinian world, were seen as regressive. They have distinctly animalistic traits, not least in the case of the blond youth on all fours.

The exceptional characterization of the women as being openly able to challenge their prospective mates for supremacy may well be linked to the French feminist ideas of around 1880. Martelli was an outspoken liberal and supporter of women's causes, not least those of prostitutes, whom he saw as brutalized by the sexual desires of men. 'Brutalized' is itself a loaded word in this post-Darwinian context.

Degas's painting is therefore not a simple homage to classical antiquity in the traditional manner of academic history paintings. It stands in a complex relationship with what was known about a remarkable early society and its potential significance for contemporary issues. Politics, feminism and anthropology are all in the artistic mix.

It is worth noting that the first of Baron Pierre de Coubertin's modern Olympic Games, held in Athens in 1896, included only male athletes. Women competitors were admitted four years later to the second Olympics in Paris, that most modern and political of contemporary cities. Yet unlike Sparta, the women did not compete directly with the men.

Martin Kemp is research professor in the history of art at the University of Oxford, OX11PT, UK, and author of The Human Animal in Western Art and Science. 